\title{
ANALISIS KUALITATIF DAN KUANTITATIF KANDUNGAN BORAKS PADA BAKSO TUSUK DI WILAYAH KABUPATEN GUNUNGKIDUL PROVINSI DAERAH ISTIMEWA YOGYAKARTA
}

\section{QUALITATIVE AND QUANTITATIVE ANALYSIS OF BORAX IN SATAI MEATBALL IN THE DISTRICT OF GUNUNGKIDUL PROVINCE SPECIAL REGION OF YOGYAKARTA}

\author{
Sabtanti Harimurti*, Asep Setiyawan \\ Laboratorium Kimia Farmasi: Program Studi Farmasi, Fakultas Kedokteran dan Ilmu Kesehatan, \\ Universitas Muhammadiyah Yogyakarta, Jl. Brawijaya, Tamantirto, Kasihan, Bantul, Yogyakarta, \\ INDONESIA, 55183
}

Naskah diterima tanggal 2 Agustus 2019

\begin{abstract}
Food is one source of energy for the human body. Healthy food contains high quality of nutrient so that affecting human health. One of the popular foods and frequently added harmful substance is satai meatball, so this kind of food becoming unhealthy. The objective of this research is to determine the availability and the concentration of borax in the satai meatball that is sold in the district of Gunungkidul, Province of Daerah Istimewa Yogyakarta. The type of this research is a descriptive laboratory, and Cluster Sampling was used for collecting the sample. Decomposition test, colour test using turmeric paper, and flame test, was used for qualitative analysis. Meanwhile, acid-base titration was performed to analyze the concentration of the borax inside the satai meatball. Base on the qualitative and quantitative analysis, all of the satai meatball sample that has been sold in the district of Gunungkidul Daerah Istimewa Yogyakarta containing borax. The borax concentration was ranged between $0.34 \%$ to $3.41 \%$.
\end{abstract}

Keywords: Satai meatball, borax, decomposition test, flame test, test acid-base titration

\begin{abstract}
ABSTRAK
Makanan adalah salah satu sumber energi bagi tubuh manusia. Makanan yang baik adalah makanan yang memiliki tingkat gizi yang tinggi sehingga berpengaruh pada kualitas kesehatan manusia. Salah satu makanan yang sedang digemari dan sering ditambahkan zat berbahaya adalah bakso tusuk. Penelitian ini dilakukan untuk mengetahui seberapa lama bakso tusuk dapat dikonsumsi dan disimpan pada suhu ruang dan mengetahui ada tidaknya kandungan boraks pada bakso tusuk serta mengukur kadar boraks pada bakso tusuk di wilayah Kabupaten Gunungkidul, Provinsi Daerah Istimewa Yogyakarta. Jenis penelitian yang digunakan adalah deskriptif laboratorik dengan pemeriksaan laboratorium secara kualitatif dengan metode pembusukan, uji warna kertas tumerik dan nyala api sedangkan secara kuantitatif dengan metode titrasi asam basa. Teknik pengambilan sampel pada penelitian ini adalah cluster sampling. Hasil analisis kualitatif dan kuantitatif menunjukan seluruh sampel bakso tusuk di Kabupaten Gunungkidul Provinsi Daerah Istimewa Yogyakarta, positif mengandung boraks. Kadar boraks berkisar antara 0,34\%-3,41\%.
\end{abstract}

Kata Kunci: Bakso tusuk, boraks, uji kebusukan, uji nyala, uji titrasi asam basa.

\section{PENDAHULUAN}

Makanan adalah salah satu sumber energi bagi tubuh manusia. Makanan yang baik adalah makanan yang memiliki gizi yang tinggi, sehingga berpengaruh pada tingkat kesehatan manusia. Makanan yang saat ini sedang marak dan digemari masyarakat dari berbagai kalangan

Alamat korespondensi :

sabtanti@umy.ac.id adalah bakso. Bakso merupakan hasil olahan daging, baik daging sapi, ayam, ikan maupun udang. Maraknya penggemar bakso terutama bakso tusuk saat ini, membuat pedagang maupun produsen bakso tusuk menambahkan zat tambahan (food additive) untuk menarik pembeli dan untuk mengawetkan. Salah satu zat kimia yang sering ditambahkan dalam makanan adalah boraks atau natrium tetraboraks 
(Syamadi, 2002; Yuliarti, 2007). Boraks adalah senyawa berbentuk kristal putih tidak memiliki bau dan stabil pada suhu ruangan. Boraks biasanya digunakan untuk bahan pembuat deterjen dan antiseptik. Mengkonsumsi boraks tidak berdampak buruk secara langsung karena boraks akan terakumulasi dalam tubuh sedikit demi sedikit sehingga menyebabkan toksik pada kadar tertentu (Bolt et al, 2012; Khamid, 2006; Environmental Protection Agency. 2006).

Pemerintah melalui Peraturan Menteri Kesehatan ( Permenkes) R I No 235/Menkes/VI/1984 tentang bahan tambahan makanan, memperkuat larangan penggunaan boraks dalam makanan. Sering mengkonsumsi makanan yang menggandung boraks akan menyebabkan gangguan otak, hati, dan ginjal, dalam jumlah tertentu boraks menyebabkan demam, anuria (tidak terbentuknya urin), koma, merangsang sistem saraf pusat, menimbulkan depresi, sianosis, tekanan darah turun, kerusakan ginjal, pingsan bahkan kematian.

Melihat minat konsumsi bakso yang sangat luas pada kalangan masyarakat semua golongan dan dikuti oleh banyaknya bakso tusuk yang dijajakan di setiap sudut tempat keramaian maka dalam penelitian ini akan dilakukan analisis kualitatif dan kuantitatif kandungan boraks pada bakso tusuk yang dijajakan di wilayah Kabupaten Gunungkidul Provinsi Daerah Istimewa Yogyakarta.

\section{METODE PENELITIAN \\ Alat}

Alat penelitian yang digunakan diantaranya beker glass, mortir dan stemper, buret, cawan porselen, erlenmeyer, labu ukur, pipet volume , pipet ukur , corong, gelas ukur , klem dan solatif, korek api.

\section{Bahan}

Air yang digunakan dalam preparasi sampel bakso tusuk adalah air bebas $\mathrm{CO}_{2}$ yang dibuat sendiri dengan cara memanaskan air suling. Asam klorida $(\mathrm{HCl})$ pekat $37 \%$, natrium hidroksida $(\mathrm{NaOH})$, asam oxalat $\left(\mathrm{H}_{2} \mathrm{C}_{2} \mathrm{H}_{4}\right)$, asam sulfat $\left(\mathrm{H}_{2} \mathrm{SO}_{4}\right)$, indikator phenolphthalein (PP), dan indikator methyl orange (MO) diperoleh dari Merk Jerman. Borak yang dipakai adalah borak yang dijual di toko makanan. Sampel bakso tusuk diambil dari seluruh kecamatan di Kabupaten Gunungkidul Provinsi Daerah Istimewa Yogyakarta. Jumlah total sample ada 36 sampel yang mewakili 18 kecamatan, yaitu Kecamatan Patuk, Playen, Wonosari, Semin, Tepus, Semanu, Girisubo, Rongkop, Ponjong, Karangmojo, Ngawen, Nglipar, Gedangsari, Saptosari, Tanjungsari, Purwosari, Paliyan, dan Panggang. Sampel diambil dari pedagang bakso tusuk yang dijajakan keliling. Penelitian ini dilaksanakan pada bulan Oktober hingga Desember 2015. Populasi dalam penelitian ini adalah seluruh bakso yang dijual oleh pedagang bakso tusuk di wilayah Kabupaten Gunungkidul Provinsi Daerah Istimewa Yogyakarta. Sedangkan sampel dalam penelitian ini adalah bakso tusuk yang dijual oleh 2 pedagang bakso tusuk dari setiap kecamatan yang ada di wilayah Kabupaten Gunungkidul Provinsi Daerah Istimewa Yogyakarta.

\section{Metode}

\section{Pengambilan Sampel}

Pengambilan sampel dilakukan dengan cara mengambil bakso tusuk dari pedagang bakso tusuk, kemudian dimasukkan kedalam plastik berklip, dibawa ke laboratorium untuk dilakukan prosedur analisis kualitatif dan kuantitatif kandungan boraks.

\section{Preparasi Sampel}

Preparasi sampel bakso tusuk yaitu dengan menimbang dan mencatat berat per satu bulat bakso tusuk secara seksama. Sampel kemudian dihaluskan dengan mortir kemudian ditambahkan air bebas $\mathrm{CO}_{2}$ sebanyak $50 \mathrm{ml}$ dan disaring menggunakan kertas saring. Filtratnya dikumpulkan untuk kemudian dianalisis.

3. Pengujian

a. Uji Pembusukan

Uji Pembusukan dilakukan dengan cara sampel yang telah diambil dari pedagang langsung diletakkan pada kertas aluminium foil untuk diamati proses pembusukannya selama 3 hari. Tiap sampel diberi label untuk memudahkan identikfikasi. Perubahan yang terjadi selama 3 hari pengamatan dicatat dalam table pengamatan (Wibowo, 2005).

\section{b. Uji Kertas Turmerik}

Pada pengujian ini dilakukan dengan membuat kertas tumerik terlebih dahulu dengan cara kunyit ukuran sedang dipotong-potong, dibersihkan dan ditumbuk kemudian disaring sehingga diperoleh cairan kunyit berwarna kuning. Kertas saring dipotong dan dimasukan ke dalam cairan kunyit kemudian keringkan. Hasil dari proses ini disebut kertas tumerik. Sebagai kontrol positif, boraks ditimbang sebanyak 100 mg kemudian ditambahkan $50 \mathrm{ml}$ aquadest. Larutan yang berisi campuran boraks dan air tersebut diteteskan ke kertas tumerik dan dikeringkan.

Warna kemerahan (Depkes, 1993) yang dihasilkan pada kertas tumerik tersebut adalah sebagai kontrol positif. Filtrat dari baso tusuk yang sudah dipreparasi sebelumnya diteteskan pada kertas turmerik dan selanjutnya dilakukan pengeringan. Setelah kering kemudian diamati apakah warna yang dihasilkan sama dengan kontrol positif, jika warna ynag dihasilkan sama dengan kontrol positif maka sampel bakso 
tersebut positif mengandung boraks.

c. Uji Nyala Api

Uji Nyala Api dilakukan dengan memasukkan $5 \mathrm{ml}$ filtrat yang telah dipreparasi, kemudian diuapkan di penangas air setelah menguap kemudian ditambahkan 10 tetes $\mathrm{H}_{2} \mathrm{SO}_{4}$ pekat dan metanol $96 \%$ sebanyak $2 \mathrm{ml}$ dalam wadah (cawan penguap) kemudian dibakar, warna api kehijauan menunjukkan adanya senyawa boraks pada sampel (Clarke, 2004; Roth, 1988)

\section{d. Titrasi Asam Basa}

Analisis kuantitatif kandungan borak dilakukan dengan metode asidimetri (Mendham, 2000). Asam yang dipakai dalam penelitian ini adalah asam klorida $(\mathrm{HCl})$. $\mathrm{HCl}$ sebelum digunakan dibakukan dulu dengan baku sekunder $\mathrm{NaOH}$. Dimana $\mathrm{NaOH}$ sebelum digunakan dibakukan dengan baku primer asam oksalat. Air yang digunakan dalam peneltian ini adalah air bebas $\mathrm{CO}_{2}$ yang dibuat dengan cara mendidihkan aquades yang kemudian disimpan dalam wadah yang tertutup atau dibuat baru sebelum digunakan. Titrasi dilakukan sebanyak $3 x$ untuk mendapatkan hasil yang baik dengan menggunakan Methyl Orange (MO) sebagai indicator saat melakukan titrasi penetapan kadar borak dalam sampel. Kadar borak pada sampel dithitung menggunakan persamaan berikut:

$$
\text { Kadar boraks }=\frac{5 \times \mathrm{V} \times \mathrm{N} \times \mathrm{BE}}{\text { berat sampel }(\mathrm{mg})} \times 100 \%
$$

\section{HASIL DAN PEMBAHASAN}

Penyediaan jajanan atau makanan yang halal dan bergizi merupakan kewajiban yang harus dilakukan oleh pedagang atau produsen untuk memenuhi kebutuhan konsumen. Bahan tambahan berbahaya sering ditambahkan ke dalam makanan oleh pedagang atau produsen untuk mendapatkan keuntungan pribadi. Salah satu contoh makanan yang sering ditemukan bahan tambahan berbahaya adalah bakso tusuk, yang banyak dijajakan dipinggir jalan. Bahan berbahaya yang sering ditemukan pada bakso tusuk adalah boraks. Pedagang menggunakan boraks untuk mengenyalkan dan mengawetkan bakso agar tahan lebih lama. Sifat boraks sebagai antiseptik dimanfaatkan sebagai pengawet.

Hasil penelitian yang dilakukan Suci (2009) menyatakan bahwa pada umumnya anak sekolah sering tidak jajan di kantin sekolah, tetapi cenderung memilih jajanan yang dijual di luar pagar sekolah. Hal ini akan mengakibatkan terpaparnya para pelajar dengan makanan yang tidak sehat yang dapat membahayakan kesehatan para pelajar tersebut. Menurut Nurkholidah dkk (2012), berdasarkan hasil penelitian terhadap 17 pedagang bakso tusuk yang berjualan di lingkungan Sekolah Dasar di Kecamatan Bangkinang dilaporkan bahwa hampir seluruh pedagang menggunakan boraks pada produk bakso tusuk dengan kandungan tertinggi 2,32 mg/g sampel.

Analisa secara kualitatif yang dilakukan pada penelitian ini dilakukan dengan uji kertas tumerik, uji nyala dan disertai uji pembusukan. Hasil pemeriksaan kualitatif boraks pada sampel seperti dirangkum pada tabel 1. Uji pembusukan sampel dianalisis dengan mengamati perubahan sampel seperti perubahan bentuk, warna, bau, tekstur dan munculnya belatung maupun jamur selama disimpan pada suhu kamar dalam waktu 3 hari. Hasil menunjukan bahwa rata-rata sampel yang mengalami perubahan signifikan terjadi pada hari ketiga, namun ada 8 sampel yang menunjukan perubahan lebih besar pada hari pertama. Perubahan yang terjadi pada sampel tersebut berupa perubahan bentuk seperti berair, berlendir, berbeda dengan bentuk bakso pada umumnya. Sampel juga mengalami perubahan warna menjadi kecoklatan, hitam pekat, dan putih pucat. Belatung dan jamur juga banyak tumbuh pada sampel. Berbeda dengan 28 sampel lainnya yang relatif lebih lama dalam mengalami perubahan. Rata-rata 28 sampel tidak mengalami perubahan bentuk (masih utuh), perubahan warna, dan tekstur.

Menurut Wibowo (2005), parameter yang dapat digunakan untuk menilai uji kebusukan yaitu penampakan atau bentuk, warna, bau, rasa, dan tekstur. Bentuk bulat halus, berukuran seragam, bersih dan cemerlang, tidak kusam, sedikit pun tidak tampak berjamur, dan tidak berlendir. Cokelat muda cerah atau sedikit agak kemerahan atau cokelat muda atau abu-abu. Warna tersebut merata tanpa warna lain yang mengganggu (jamur) Bau khas daging segar rebus dominan, tanpa bau tengik, asam, basi atau busuk. Bau bumbu cukup tajam. Rasa daging dominan dan rasa bumbu cukup menonjol tapi tidak berlebihan. Tidak terdapat rasa asing yang mengganggu. Kompak, elastis, kenyal tetapi tidak liat atau membal, tidak ada serat daging, tidak lembek, tidak basah berair, dan tidak rapuh. Hal terssebut dapat menjadi parameter pembusukan.

Meskipun 8 sampel mengalami pembusukan lebih cepat yaitu pada hari pertama pengujian, namun uji pembusukan yang dilakukan belum membuktikan bahwa sampel mengandung boraks atau tidak karena ada faktor lain yang mempengaruhi uji ini. Faktor yang mempengaruhi uji pembusukan adalah banyaknya daging yang digunakan pada bakso tusuk, semakin banyak daging yang digunakan semakain cepat pembusukan terjadi dimungkinkan pada sampel yang diuji kandungan daging bervariasi sehingga mempengaruhi lama 
pembusukan. Kandungan bahan pengawet lain yang biasa di tambahkan seperti formalin juga mempengaruhi pembusukan sehingga untuk menguatkan hipotesis penelitian ini maka dilakukan uji selanjutnya yang lebih spesifik yaitu mendeteksi adanya kandungan boraks pada sampel.

Hasil uji kertas tumerik pada penelitian ini adalah sebanyak 36 sampel yang diuji menunjukan noda yang sama dengan kontrol positif, sementara tidak ada satupun sampel menunjukan noda yang sama dengan kotrol negatif. Sampel dikatakan positif mengandung boraks jika memiliki noda yang sama dengan kontrol positif, sedangkan sampel dikatakan negatif mengandung boraks jika memiliki noda yang sama dengan kontrol negatif. Prinsip uji ini adalah bahwa ekstrak turmerik yang menempel di kertas saring mengandung kurkumin. Kurkumin memiliki dua bentuk tautomer: keton dan enol. Gugus keton dan hidroksil berinteraksi dengan asam borat menghasilkan senyawa berwarna merah yang disebut rososianin. Bentuk komplek kurkurmin dengan borat bisa dilihat pada Gambar 1 berikut.

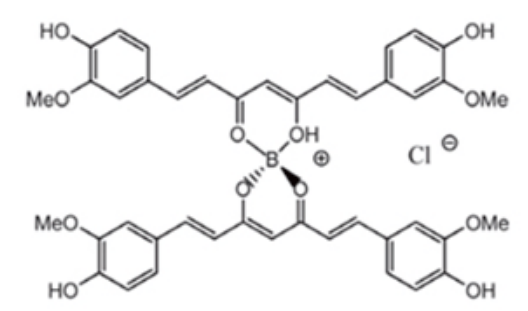

\section{Gambar 1. Komplek kurkumin dengan borat membentuk rososianin (Grynkiewicz dan Ślifirski, 2012)}

Prinsip pengujian kandungan boraks dengan nyala api yaitu dengan melihat perubahan warna nyala api, karena beberapa logam memberikan warna nyala yang khas bila dibakar pada api oksidasi menghasilkan warna api warna biru. Pembakaran akan memberikan warna nyala hijau jika positif mengandung boraks (Clarke, 2004). Pada uji nyala ditambahkan asam sulfat pekat $\left(\mathrm{H}_{2} \mathrm{SO}_{4}\right)$ tujuannya adalah agar memberi suasana asam pada arang sampel. Hasil pada Tabel 1 menunjukan bahwa uji nyala api terhadap sampel hanya mendeteksi 4 sampel dari 36 sampel yang diuji. Sampel yang terdeteksi oleh uji nyala api meliputi 4 sampel positif ditunjukan dengan nyala api warna hijau setelah penambahan methanol dan asam sulfat $\left(\mathrm{H}_{2} \mathrm{SO}_{4}\right)$ pekat yang dibakar.

Dari hasil penelitian ini banyak sampel yang tidak teridentifikasi warna nyala hijau melainkan warna nyala biru kekuningan/merah kekuningan. Banyaknya sampel yang tidak terdeteksi kandungan boraks dimungkinkan karena warna nyala hijau tertutup oleh warna merah kekuningan hasil pembakaran senyawa pengganggu dari sampel bakso tusuk. Hal ini terjadi dikarenakan dalam proses uji nyala api tidak melalui proses penghilangan komponen atau senyawa pengganggu.

Menurut data Tabel 2 bahwa semua sampel yang diuji dengan titrasi asam basa (asidimetri) dan telah dilakukan perhitungan kadar, menunjukan data tersebut positif mengandung boraks dengan kadar yang bervariasi. Setelah diketahui kadar setiap sampel maka dapat diketahui rata-rata kadar sampel, jumlah \% kadar sampel, kadar tertinggi pada sampel dan kadar terendah pada sampel. Kadar yang diperoleh dari data analisis kuantitatif pada Tabel 2 berkisar antara 0,34\%-3,41\% dengan jumlah persen kadar pada penelitian ini adalah sebanyak $62,01 \%$ dan rata-rata kadar sebanyak $1,72 \%$. Penelitian ini menunjukan bahwa semua sampel yang diuji dengan titrasi asam basa positif mengandung boraks.

Berdasarkan data penelitian ini menunjukan bahwa semua sampel yang di uji positif mengandung boraks. Berbeda dengan penelitian yang dilakukan Silalahi (2010) menunjukan 10 sampel bakso di kota Medan yang diteliti menunjukkan $80 \%$ sampel yang diperiksa ternyata mengandung boraks dengan kadar yang didapatkan antara $0,08 \%-0,29 \%$. Penelitian ini juga berbeda dengan hasil penelitian yang dilakukan oleh Tubagus dan kawan-kawan pada tahun 2013 yang meneliti tentang kandungan boraks pada bakso jajanan di kota Manado dari semua sampelnya tidak mengandung boraks.

Menurut hasil pada penelitian ini bahwa semua sampel yang diuji mengandung boraks, sementara penggunaan boraks telah dilarang dengan adanya SK menteri kesehatan RI No.722/MEN.KES/PER/IX/88. Toksisitas boraks yang dinyatakan dalam LD 50 (letal dose) akut adalah 4,50-4,98 g/kg berat badan tikus. Boraks yang ditambahkan pada makanan akan diserap oleh tubuh melalui saluran pencernaan dan disimpan secara kumulatif dalam hati, otak dan testis (Winarno, 1997). Dosis Boraks yang tinggi dalam tubuh dapat menyebabkan timbulnya gejala pusing, muntah, mencret, kram perut, dan kompulsi dengan dosis kematian untuk orang dewasa 10 - 20 gram atau lebih (Syamadi, 2002).

Berdasarkan Etimine USA, Inc., Safety Data Sheet menyebutkan bahwa Boraks memiliki toksisitas yang dinyatakan dalam LD50 Oral (letal dose) sebanyak $3500 \mathrm{mg} / \mathrm{kg}-4100 \mathrm{mg} / \mathrm{kg}$ tikus, LD50 Dermal 2000 mg/kg kelinci, LC50 Inhal (letal concentration) Boric Acid $>2.03 \mathrm{mg} / \mathrm{L}$ tikus selama 4 jam, sedangkan menurut Saparinto dan Hidayati (2006) dosis tertinggi boraks yaitu 10 $\mathrm{g} / \mathrm{kgBB}-20 \mathrm{~g} / \mathrm{kgBB}$ orang dewasa dan $5 \mathrm{~g} / \mathrm{kgBB}$ 
Tabel 1. Hasil Pemeriksaan Secara Kualitatif Kandungan Boraks Pada Sampel Bakso Tusuk

\begin{tabular}{|c|c|c|c|c|c|c|}
\hline \multirow{2}{*}{ Sampel } & \multirow{2}{*}{$\begin{array}{l}\text { Kode } \\
\text { Sampel }\end{array}$} & \multicolumn{3}{|c|}{ Uji Kebusukan } & \multirow[t]{2}{*}{ Uji Tum erik } & \multirow[t]{2}{*}{$\begin{array}{c}\text { Uji } \\
\text { Nyala }\end{array}$} \\
\hline & & Hari 1 & Hari 2 & Hari 3 & & \\
\hline Patuk 1 & 1,1 & $\begin{array}{l}\text { Wama coklat,s edikit basah, } \\
\text { bau basi }\end{array}$ & Utuh,warna coklat; Jamur + & $\begin{array}{l}\text { Utuh, Jamur +(warna orange), } \\
\text { kering. }\end{array}$ & + & TD \\
\hline Patuk 2 & 1,2 & $\begin{array}{l}\text { Utuh,kering warna pucat, } \\
\text { Jamur+, Semut + }\end{array}$ & $\begin{array}{l}\text { Utuh , warna coklat pucat, } \\
\text { Jamur +, Bau basi }\end{array}$ & $\begin{array}{c}\text { Utuh, putih pucat, kering, Jamur } \\
++\end{array}$ & + & TD \\
\hline Playen 1 & 2,1 & $\begin{array}{c}\text { Utuh, kering, belatung - ,Jamur } \\
-\end{array}$ & $\begin{array}{c}\text { Kering, wama putih, Belatung- } \\
\text {, Jamur - }\end{array}$ & $\begin{array}{c}\text { keras,tidak ada bau, belatung -, } \\
\text { jamur - }\end{array}$ & ++ & TD \\
\hline Playen 2 & 2,2 & Utuh,kering, belatung -, jamur & $\begin{array}{c}\text { Kering,keras Belatung -, } \\
\text { Jamur - }\end{array}$ & $\begin{array}{c}\text { keras,tidak ada bau, belatung -, } \\
\text { jamur - }\end{array}$ & ++ & TD \\
\hline Wonosari 1 & 3,1 & Utuh, kering, Belatung -, jamur & $\begin{array}{c}\text { Kering,keras, Belatung -, } \\
\text { Jamur - }\end{array}$ & kering,keras, belatung -, jamur + & ++ & TD \\
\hline Wonosari 2 & 3,2 & $\begin{array}{c}\text { Belatung -, jamur + Mulai } \\
\text { menghitam }\end{array}$ & $\begin{array}{l}\text { Warna hitam,utuh Jamur +++, } \\
\text { Belatung - }\end{array}$ & $\begin{array}{c}\text { wama hitam, bau busuk jamur +++, } \\
\text { belatung - }\end{array}$ & + & TD \\
\hline Semin 1 & 4,1 & $\begin{array}{c}\text { Mulai busuk, Belatung +, } \\
\text { Jamur }+\end{array}$ & $\begin{array}{c}\text { Warna cokat, Jamur ++, } \\
\text { Belatung ++ }\end{array}$ & $\begin{array}{c}\text { warna coklat jamur }+++, \text { belatung } \\
+++\end{array}$ & + & TD \\
\hline Semin 2 & 4,2 & $\begin{array}{c}\text { Utuh, wama coklat } \\
\text { muda, Belatung }+, \text { J amur }+\end{array}$ & $\begin{array}{l}\text { Utuh, warna kecoklatan, } \\
\text { Jamur +, Belatung - }\end{array}$ & $\begin{array}{c}\text { utuh, warna kecoklatan, jamur ++, } \\
\text { belatung - }\end{array}$ & + & TD \\
\hline Tepus 1 & 5,1 & $\begin{array}{l}\text { Jamur +++, belatung - } \\
\text { Berlendi r,mulai rus ak }\end{array}$ & $\begin{array}{l}\text { Jamur +++, be latung - } \\
\text {,warna coklat, berpori-pori }\end{array}$ & $\begin{array}{c}\text { Jamur +++++ Belatung -, } \\
\text { berlendir, rusak }\end{array}$ & ++ & TD \\
\hline Tepus 2 & 5,2 & $\begin{array}{c}\text { Jamur+, Berlendir, basah bau } \\
\text { basi }\end{array}$ & $\begin{array}{c}\text { Jamur }+, \text { Kering, wama } \\
\text { coklat,bau basi }\end{array}$ & $\begin{array}{c}\text { Utuh, jamur +, Warna hitam, } \\
\text {,kering }\end{array}$ & + & TD \\
\hline Semanu 1 & 6,1 & $\begin{array}{l}\text { Belatung }+, \text { tekstur berair, } \\
\text { mulai membusuk }\end{array}$ & $\begin{array}{l}\text { Belatung ++ wama } \\
\text { kehijauan,mulai hancur }\end{array}$ & $\begin{array}{l}\text { Belatung }+++ \text {, wama lebih hijau, } \\
\text { tidak berbentuk }\end{array}$ & + & TD \\
\hline Semanu 2 & 6,2 & $\begin{array}{c}\text { Utuh, keras,, jamur }+ \text {, belatung } \\
-\end{array}$ & $\begin{array}{l}\text { Utuh ,warna cok lat,bentuk } \\
\text { tidak, jamur ++, belatung + }\end{array}$ & $\begin{array}{l}\text { Wama coklat,tidak berbentuk } \\
\text { jamur }+++, \text { belatung }++\end{array}$ & ++ & TD \\
\hline Girisubo 1 & 7,1 & Utuh, Jamur -, belatung - & Utuh, Menghitam, jamur + & $\begin{array}{c}\text { Jamur -, belatung -, Bau sedik it } \\
\text { bus uk }\end{array}$ & + & TD \\
\hline Girisubo 2 & 7,2 & $\begin{array}{l}\text { Jamur }+ \text {, belatung - } \\
\text { Kering, utuh, wama putih pucat }\end{array}$ & $\begin{array}{l}\text { Jamur }+ \text {, belatung - } \\
\text { Kering,utuh,warna putih pucat }\end{array}$ & $\begin{array}{l}\text { Jamur }+++ \text {, belatung - } \\
\text { Kering, utuh,warna putih pucat }\end{array}$ & + & TD \\
\hline Rongkop 1 & 8,1 & $\begin{array}{c}\text { Jamur + belatung -, Warna } \\
\text { cok lat, lembek }\end{array}$ & $\begin{array}{c}\text { Jamur }++ \text {, belatung -, } \\
\text { Berwama coklat }\end{array}$ & $\begin{array}{c}\text { Jamur }+++ \text {, belatung }- \text {, Coklat } \\
\text { kehitaman }\end{array}$ & + & TD \\
\hline Rongkop 2 & 8,2 & $\begin{array}{l}\text { Warna coklat, Utuh jamur +, } \\
\text { belatung - }\end{array}$ & $\begin{array}{l}\text { Jamur +, belatung -, } \\
\text { Utuh,tidak rusak }\end{array}$ & Jamur +++, Hancur, belatung - & + & TD \\
\hline Ponjong 1 & 9,1 & $\begin{array}{c}\text { Warna pucat,s edikit berair, } \\
\text { Belatung }+\end{array}$ & $\begin{array}{l}\text { Tidak berbentuk, hancur, warna } \\
\text { kuning, belatung ++ }\end{array}$ & $\begin{array}{c}\text { Hancur, Wama kuning, Belatung } \\
\qquad+++\end{array}$ & + & TD \\
\hline Ponjong 2 & 9,2 & $\begin{array}{l}\text { Tekstur berair,mulai busuk, } \\
\text { Belatung-- }\end{array}$ & Utuh, mulai busuk, Belatung + & Utuh, busuk, Belatung +++ & ++ & TD \\
\hline Karang mojo & 10,1 & $\begin{array}{c}\text { Utuh, warna coklat, Jamur }+ \text {, } \\
\text { Belatung }+\end{array}$ & $\begin{array}{l}\text { Tidak berbentuk,bakso } \\
\text { meleleh,warna kehijauan, } \\
\text { belatung }+, \text { Jamur }+\end{array}$ & $\begin{array}{c}\text { Bakso jadi cair, warna hijau, Jamur } \\
+++ \text { belatung }+++\end{array}$ & ++ & + \\
\hline$\underset{2}{\text { Karang }} \mathrm{mojo}$ & 10,2 & $\begin{array}{l}\text { Wama hitam,mulai hancur, } \\
\text { mulai busuk, Belatung }++ \\
\text { Coklat kehitaman, mulai }\end{array}$ & $\begin{array}{l}\text { Bakso hancur, Sebagian } \\
\text { dimakan belatung } \\
\text { Coklat kehitaman, mulai }\end{array}$ & Bakso meleleh, Belatung ++++ & ++ & TD \\
\hline Ngawen 1 & 11,1 & $\begin{array}{c}\text { membus uk Jamur -, belatung } \\
+\end{array}$ & $\begin{array}{c}\text { membusuk, Jamur -, belatung } \\
+\end{array}$ & Utuh, Kehitaman, & + & TD \\
\hline
\end{tabular}


Tabel 2. Hasil Uji Kuantitatif Kandungan Boraks pada Sampel Bakso Tusuk Menggunakan Titrasi Asam Basa

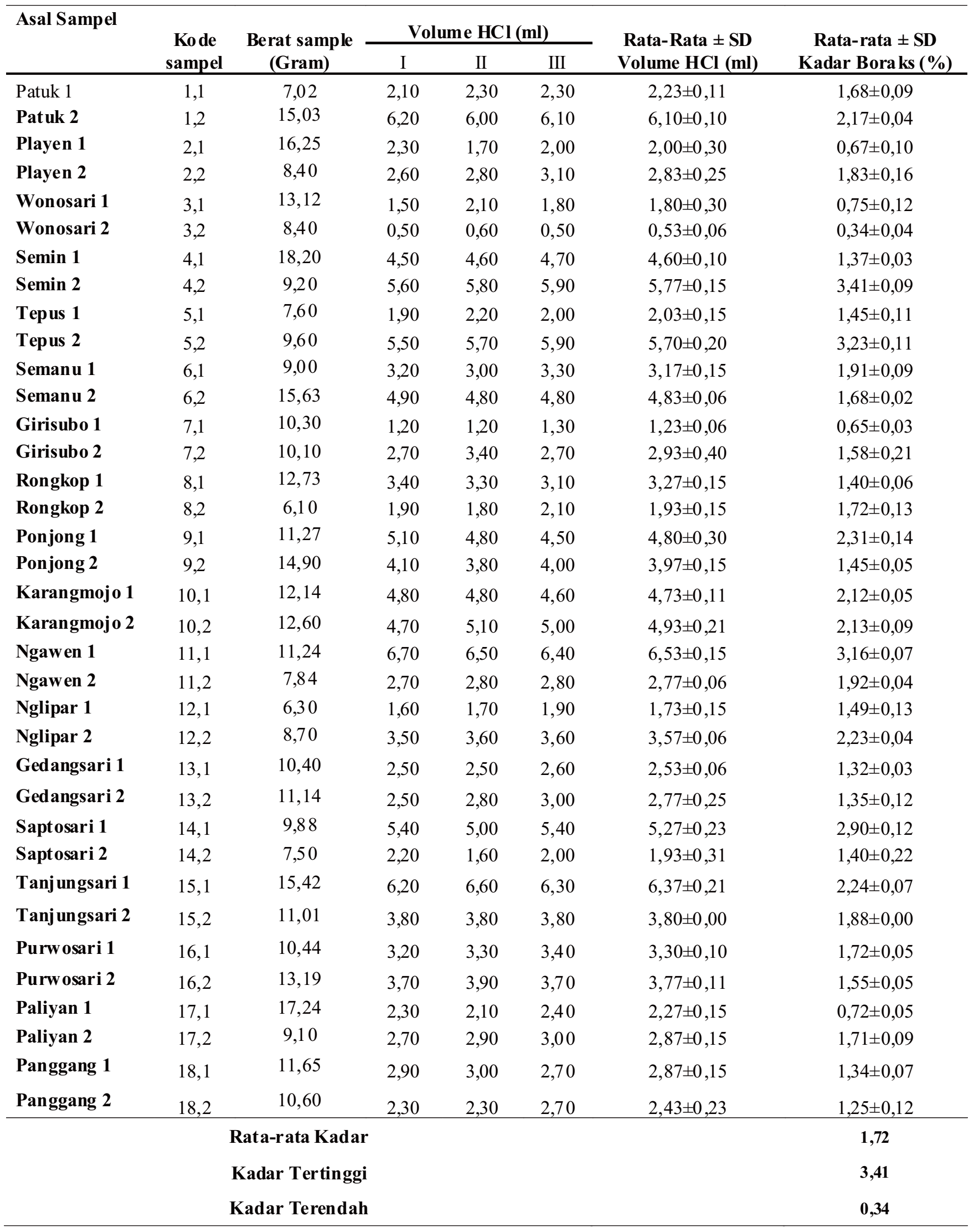


anak-anak yang menyebabkan keracunan hingga kematian.

Berdasarkan data toksisitas boraks diatas jika dibandingkan dengan hasil penelitian ini masih jauh dari dosis toksisitas. Namun jika dilihat dari sifat boraks yang mengakumulasi dalam tubuh maka kadar tersebut akan meningkat jika dikonsumsi secara terus-menerus sehingga dosis yang membahayakan dapat tercapai (Bolt et al, 2012; Khamid, 2006; Environmental Protection Agency. 2006). Oleh karena itu selayaknya bahan tambahan berbahaya seperti boraks ini, tidak lagi terkandung dalam makanan. Pengawasan ketat dari berbagai pihak juga diperlukan agar produsen atau pedagang tidak menggunakan bahan tambahan makanan yang berbahaya, sehingga makanan atau jajanan yang beredar dimasyarakat memiliki mutu yang baik untuk dikonsumsi maka kualitas kesehatan masyarakat dapat terjamin.

\section{KESIMPULAN}

Bakso tusuk yang dijual di wilayah Kabupaten Gunungkidul Provinsi Daerah Istimewa Yogyakarta tidak mengalami perubahan fisik, tekstur, bau, dan rasa setelah bakso tusuk didiamkan dalam suhu kamar selama 3 hari. Sampel bakso tusuk sebanyak 36 sampel menunjukan $100 \%$ positif mengandung boraks. Analisis kuantitatif yang telah dilakuan menunjukan bahwa kadar kandungan boraks pada bakso tusuk berkisar antara $0,34 \%-3,41 \%$.

\section{UCAPAN TERIMAKSIH}

Author mengucapkan terimaksih yang sebesar-besarnya kepada Univeritas Muhammadiyah Yogyakarta atas bantuan fasilitas labortorium untuk penelitian ini.

\section{DAFTAR PUSTAKA}

Bolt, H. M., Başaran, N., Duydu, Y., 2012. Human Environmental and Occupational Exposures to Boric Acid: Reconciliation with Experimental Reproductive Toxicity Data. Journal of Toxicology and Environmental Health, Part A. 75, 508-514.

Clarke, E. G. C., Moffat, A. C., Osselton, M. D., Widdop, B., 2004. Clarke's Analysis Of Drugs And Poisons. Pharmaceutical Press. London.

Depkes 41/MA/93. 1993. IdentifikasiBoraks dalam Makanan. dalam:Metode. Analisis. Pusat PemeriksaanObat dan $\mathrm{M}$ a k a $\mathrm{n}$ a $\mathrm{n}$. D i r e k tor a t JendralPengawasan Obat dan Makanan.Departemen Kesehatan RI, Jakarta.
Etimine USA, Inc., Safety Data Sheet, http://www.etimineusa.com/sites/etimin e u s a . com/ fi le s/SD S\% 20 $\% 20$ Decahydrate $\% 202016 \% 20$ \%202018.pdf.

Environmental Protection Agency. 2006. Report Of The Food Quality Protection Act ( $F Q P A) \quad T$ ole $r$ a $n c e$ ReassessmentEligibility Decision (Tred) For Boric Acid/Sodium Borate Salts. Environmental Protection A ge n c y, Prevention, Pesticides And Toxic Substance: United States

Grynkiewicz, G. and Ślifirski, P., 2012. Curcumin and curcuminoids in quest for medicinal status. Acta Biochimica Polonica, 59(2).

Khamid, I.R. 2006. Bahaya Boraks Bagi Kesehatan. Penerbit Kompas. Jakarta.

Mendham, J., Denney, R. C., Barnes, J. D., Thomas, M. J. K. 2000, Vogel's Quantitative Chemical Analysis (6th ed.), Prentice Hall, New York. p. 316.

Nurkholidah, Ilza M., Jose, C., 2012. Analisis Kandungan Boraks Pada Jajanan Bakso Tusuk Di Sekolah Dasar Di Kecamatan Bangkinang Kabupaten Kampar., Jurnal IImu Lingkungan, 6,134-235.

Peraturan Menteri Kesehatan Republik Indonesia No 33 Tahun 2012 Tentang Bahan Tambahan Pangan. Jakarta

Roth, H. J. 1988. Analisis Farmasi.Gadjah Mada University Press; Yogyakarta.

Saparinto, C. Hidayati, D. (2006). Bahan Tambahan Pangan. Penerbit Kanisius. Yogyakarta,

Silalahi, J.,Immanuel, M.,Labora, P., 2010. Pemeriksaan Boraks Di Dalam Bakso Di Medan. Majalah Kedoktetan Indononesia, Volume: 60, Nomor: 11, November 2010

Suci, E.S.T., 2009. Gambaran Perilaku Jajan Murid Sekolah Dasar di Jakarta. Psikobuana 2009, volume 1, No 1: 2938. Universitas Katolik Atma Jaya, Jakarta

Syamadi, R. K. 2002. Aplikasi Penggunaan $\mathrm{H}_{2} \mathrm{O}_{2}$ Dan Iradiasi Dalam Pengawetan Bakso Sapi Pada Penyimpanan Suhu Kamar. Skripsi. Fateta IPB, Bogor.

Tubagus, I., Citraningtyas, G., Fatimawali, 2013. Identifikasi dan penetapankadar boraks dalam bakso jajanan diKota Manado. PHARMACON. Jurnal IImiah Farmasi UNSRAT Vol. 2 No. 040. p. 142-148.

Wibowo, S. 2005. Pembuatan Bakso Daging dan Bakso Ikan. Penebar Swadaya, Jakarta.

Yuliarti, N.. 2007. Awas bahaya di balik lezatnya makanan. PenerbitAndi. Yogyakarta. 